\title{
Ocorrências de Th-ETR do tipo Thorium Veins associadas à Suíte Apiaú, centro de Roraima, Cráton Amazônico
}

\author{
Leonardo Aguiar (leonardo.aguiar@cprm.gov.br) \\ Sérgio Roberto Almada da Silva (sergio.almada@cprm.gov.br) \\ Paulo Roberto Santos Lopes (paulo.lopes@cprm.gov.br) \\ Vanessa da Silva Oliveira (vanessa.silva@cprm.gov.br) \\ Michele Zorzetti Pitarello (michele.pitarello@cprm.gov.br) \\ Marina Nascimento Ramos (marina.ramos@cprm.gov.br)
}

Serviço Geológico do Brasil - CPRM, SUREG-MA - Superintendência Regional de Manaus

\begin{abstract}
The central Roraima state presents a great potential for mineralization related to alkaline rocks, notably Th, REE, $P$ and $B a$. Besides supergene concentrations in laterites, large areas with anomalous radioactivity and hydrothermally altered rocks were found. The presence of alkaline metasomatism, quartz, K-feldspar, Fe oxides, Th-REE-P-Ba-bearing minerals, hydrothermal breccias and veins are noteworthy. These characteristics resemble those of Thorium Veins mineralization model.
\end{abstract}

Keywords: REE. Alkaline rocks. Thorium veins.

Palavras-chave: ETR. Rochas alcalinas. Veios de tório.

\section{INTRODUÇÃO}

Desde o final da década de 1970, o estado de Roraima é descrito com potencial para abrigar depósitos de minerais estratégicos associados a rochas alcalinas (ETR, Nb, P, U, entre outros). À época, foram descobertas anomalias radioativas entre os rios Apiaú e Branco (CPRM, 1978; MOURÃO, 1984). Iniciaram-se então os trabalhos de prospecção geoquímica e mapeamento litológico de semi-detalhe dessas anomalias na região da Serra do Repartimento e à NW desta área (Bloco Apiaú) sendo descritas ocorrências de $\mathrm{Ba}, \mathrm{P}, \mathrm{Nb}$ e ETR associadas a rochas alcalinas (SOUZA, 1989; BORGES, 1990). Concomitantemente, foram cartografados novos corpos de rochas alcalinas e delimitadas áreas favoráveis à mineralizações de U-Th-ETR-P (BRANDÃO; FREITAS, 1994).

Devido ao potencial regional, em 2010 o Serviço Geológico do Brasil - CPRM retomou os trabalhos nessa região com os projetos Fosfato e Terras Raras do Brasil (TAKEHARA, [2019?], no prelo) responsável pela prospecção geoquímica e mapeamento litoestrutural de semi-detalhe da folha Campos Novos, além de delimitar novos alvos favoráveis à ocorrência de rochas fosfáticas e/ou portadoras de mineralizações de ETR.

Neste Informe Técnico são apresentados dados de campo e geoquímicos preliminares do projeto Centro-Sudeste de Roraima, ação Novas Fronteiras (em andamento). Também são descritas novas ocorrências de Th e ETR que não possuem associação espacial direta com as rochas alcalinas conhecidas.

\section{CONTEXTO GEOLÓGICO}

A área de estudo está inserida no Cráton Amazônico, Domínio Tectonoestratigráfico Guiana Central (DGC), região central do estado de Roraima (Figura 1) (REIS et al., 2003; REIS et al., 2004). O DGC é caracterizado por uma estruturação de direção NE-SW, destacada pelo alinhamento de feições geomorfológicas (cristas, vales, etc.). O desenvolvimen- 
to dessa extensa feição litoestrutural iniciou-se no Paleoproterozoico, com a colocação sin-cinemática dos granitoides das suítes Rio Urubu e Serra da Prata (FRAGA, 2002), sendo reativada até, pelo menos, o Mesozoico, no final da abertura do Atlântico Central, com a instalação e preenchimento do graben do Tacutu (EIRAS; KINOSHITA, 1988).

O embasamento na área é representado por ortognaisses e metagranitoides foliados da Suíte Rio Urubu (SRU) (1935 $\pm 5 \mathrm{Ma}$ ) e por charnockitoides da Suíte Serra da Prata (SSP) (1,94 Ga) (FRAGA; ARAÚJO; DUARTE, 1997; FRAGA; ARAÚJO, 2000; FRAGA, 2002).

No Mesoproterozoico, em torno de 1,52 Ga, colocam-se os corpos de granitos rapakivi e mangeritos da Suíte Mucajaí (SM), esta cronocorrelata e espacialmente associada com anortositos e gabro-noritos da Suíte Repartimento (SR) (SANTOS et al., 1999; FRAGA, 2002; HEINONEN et al., 2012). Ainda no Mesoproterozoico ocorre o desenvolvimento de extensas zonas de cisalhamento, com a formação de cataclasitos a milonitos de temperatura baixa a moderada. Para uma importante zona de cisalhamento nessa área, aqui chamada de zona de cisalhamento Serra do Repartimento (ZCSR), Fraga (2002) descreveu uma assimetria dextral e reversa e obteve a idade de $1264 \pm 155$ Ma para esse cisalhamento.

Já no Mesozoico, reflexos tectônicos da abertura do Atlântico Central levaram à reativação das estruturas do DGC, associada à instalação do graben do Tacutu e a intrusão de diques máficos toleíticos. Esse magmatismo possui uma idade aproximada de 200 Ma (MARZOLI et al., 1999).
Ainda no Mesozoico, durante o Albiano, ocorre a intrusão de magmas alcalinos, representados na área pelos corpos Serra do Repartimento e stocks próximos a Serra do Apiaú, sendo definida como Suíte Alcalina Apiaú por Brandão e Freitas (1994). Essa suíte é composta por sienitos, nefelina sienitos e diques de traquitos, fonolitos, nefelinitos, basanitos e lamprófiros (SANTOS et al., 1974; MONTALVÃO et al., 1975; BORGES, 1990; BRANDÃO; FREITAS, 1994; FIGUEIRÊDO, 2016). Em nefelina sienitos dessa região foram determinadas idades entre 111$116 \mathrm{Ma}$ (FIGUEIRÊDO, 2016) e $107 \pm 3 \mathrm{Ma}$ (ALMEIDA; OLIVEIRA, 2018). FIGUEIRÊDO (2016) descreve a presença de torita acessória em fonolito agpaítico dessa região.

No Cenozoico a alteração intempérica foi intensa, sendo frequente a presença de crostas lateríticas ferruginosas que, inicialmente, foram os principais alvos para a prospecção das mineralizações em questão.

Quanto aos recursos minerais, BOMFIM et al. (1974), descreveram brechas, lateritos e minerais indicativos de mineralizações de $\mathrm{Cu}$ (calcopirita e bornita) na região oeste da Serra do Repartimento. BORGES (1990) descreve ocorrências de Ba, P, Nb e ETR a sul da Serra do Repartimento com a presença de veios ricos em barita e concentrações supergênicas relacionadas ao intemperismo das rochas alcalinas. Recentemente, na região da ZCSR, CAMARO (2017) descreveu ocorrências de $\mathrm{Ti}$, Nb e ETR em veios de quartzo e rutilo associados a um intenso hidrotermalismo alcalino (fenitização), com a contribuição de fluidos do magmatismo alcalino regional.

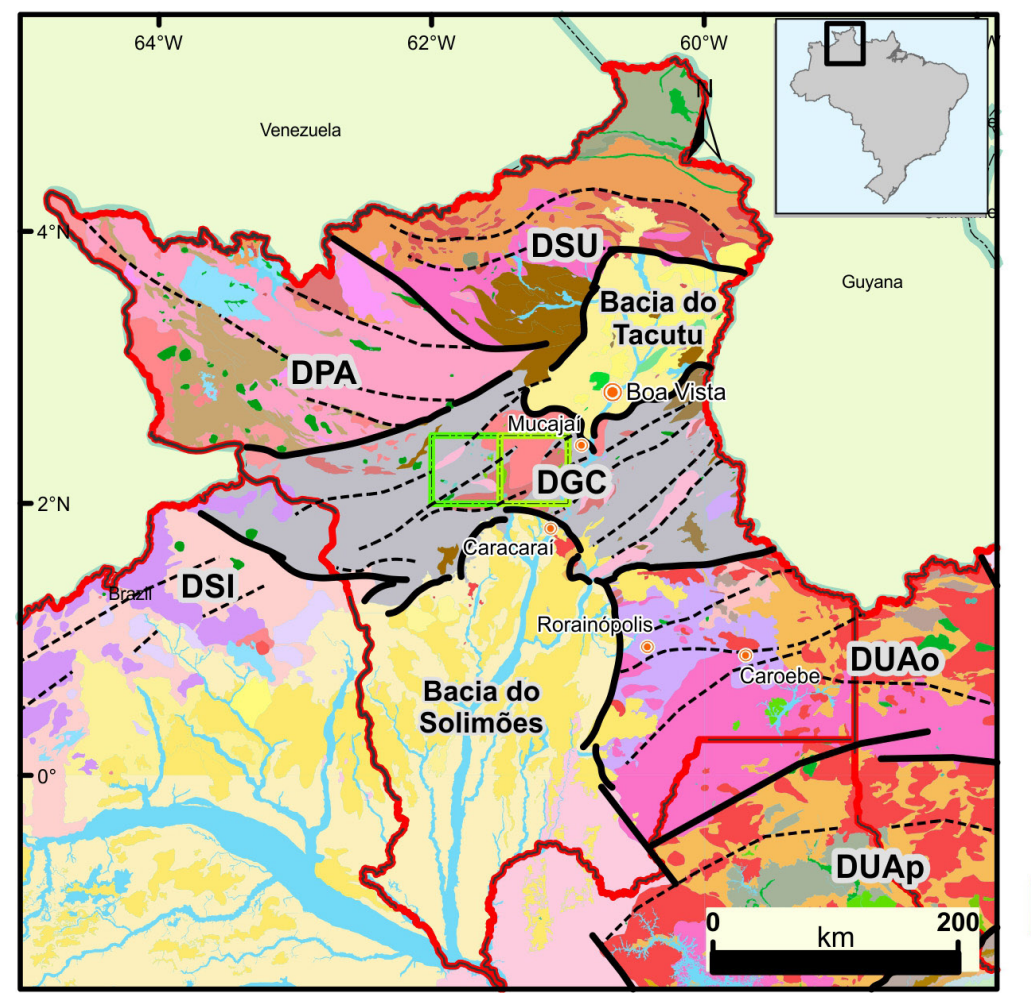

\section{LEGENDA}

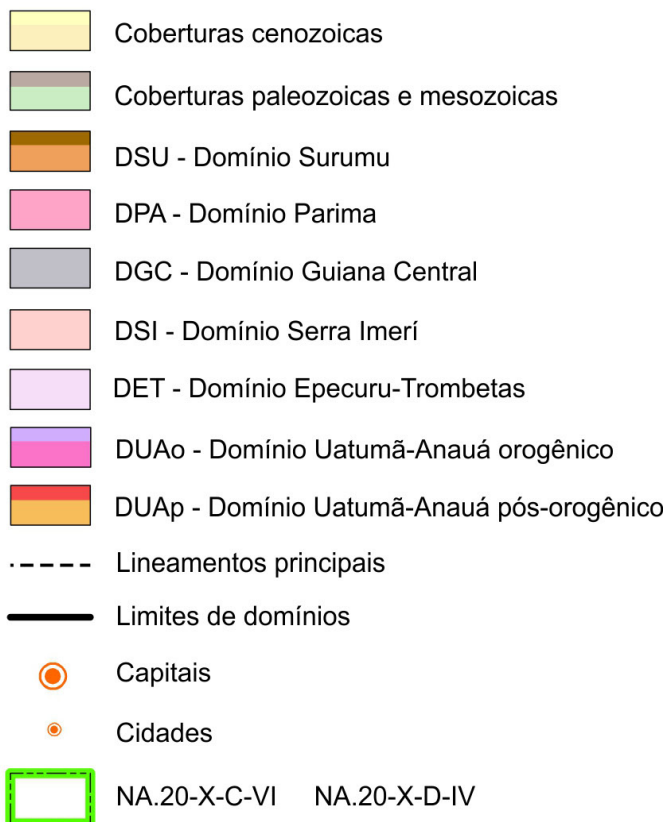

Figura 1 - Domínios geotectônicos do estado de Roraima e adjacências (REIS et al., 2003; REIS et al., 2004). 


\section{METODOLOGIA}

Para delimitar áreas com maior potencial para mineralizações relacionadas às rochas alcalinas, foram feitas revisões de projetos históricos, compilação, integração e consistência de dados petrográficos, gerados mapas de favorabilidade e definidos alvos através de modelagem espacial por lógica Fuzzy. A modelagem foi realizada com software ArcGIS, com as extensões Geostatistical Analyst, Spatial Analyst e Spatial Data Modeller (SAWATZKI et al., 2009). OLIVEIRA et al. (2016) descrevem a metodologia aplicada e os parâmetros inseridos na modelagem utilizada para seleção dos alvos nesse estudo. Esses alvos foram classificados em quatro grupos de anomalias: 1 ) associadas com corpos conhecidos e previamente cartografados de rochas alcalinas; 2) próximas de corpos alcalinos cartografados; 3 ) distantes de corpos alcalinos, e; 4) sem relação com corpos alcalinos conhecidos (Figura 2).

Além do mapeamento de alvos conhecidos, com auxílio do mapa de favorabilidade para rochas alcalinas, foram descobertos novos alvos e realizada amostragem para petrografia (laboratório de microscopia da SUREG-MA, litogeoquímica multielementar (SGS-Geosol), e Difração de raios-X (DRX) (LAMIN-MA).

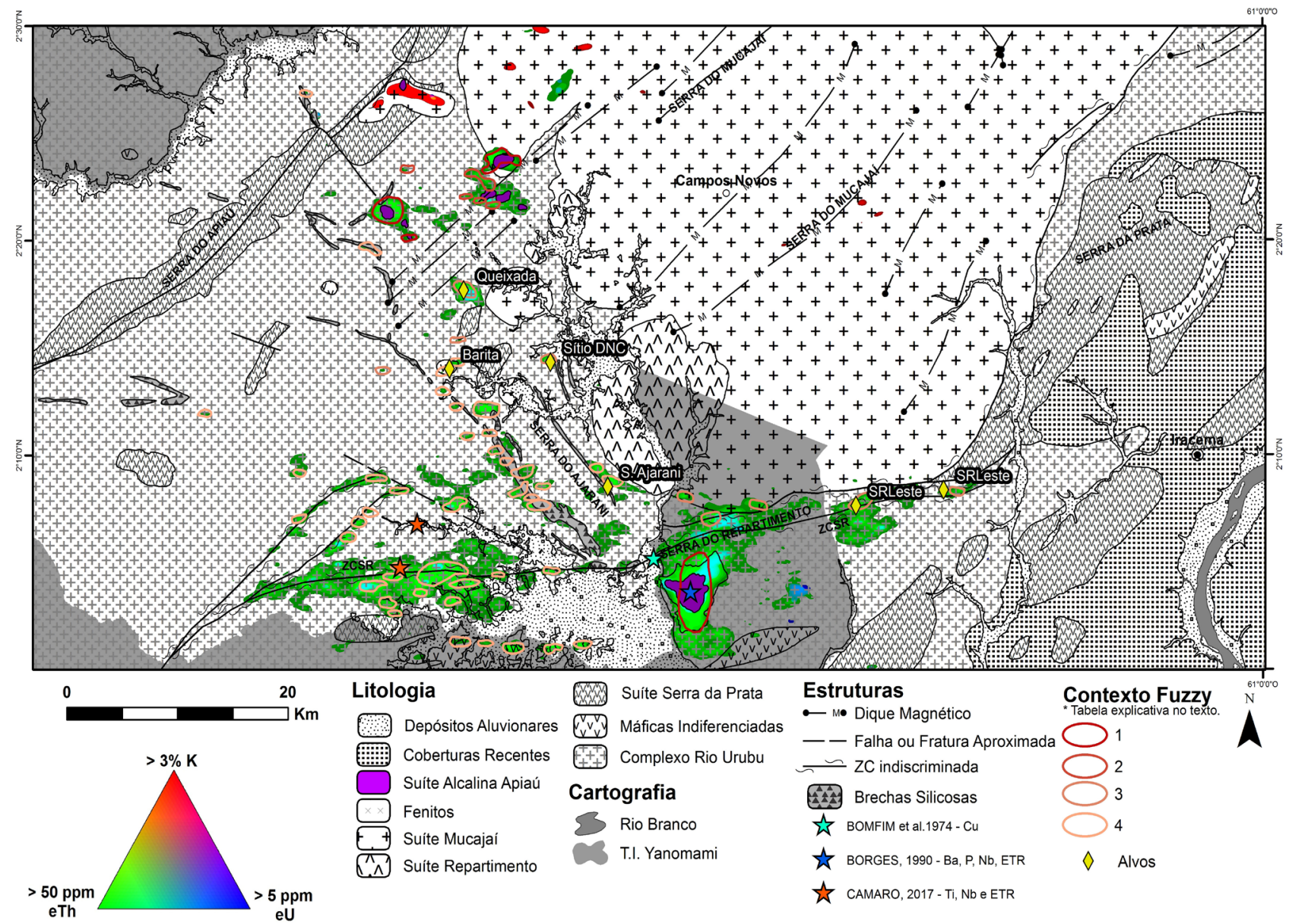

Figura 2 - Mapa geológico simplificado com destaque para os alvos, valores gamaespectrométricos anômalos e áreas extraídas da modelagem espacial.

\section{RESULTADOS}

Durante a etapa preparatória constatou-se que as rochas coletadas por Brandão e Freitas (1994) na folha Serra do Ajarani ao longo do rio Ajarani e da Serra do Ajarani apresentam diferentes graus de metassomatismo, com mineralogia típica de fenitização (i.e., metassomatismo alcalino, tipicamente de dessilicificação, podendo ser sódico, potássico ou ambos (LE BAS, 1981)). A característica mais frequente é a presença de agregados de riebeckita fibro-radiada (Figura 3A) desenvolvi- dos à custa de quartzo ou substituindo os minerais máficos. Onde a alteração foi mais intensa ocorre fenitos strictu sensu, com a substituição total de quartzo e minerais máficos por aegirina fibro-radiada e de feldspatos por microclínio avermelhado de aspecto turvo (Figura 3B). A interpretação dos dados aerogeofísicos mostrou que as anomalias gamaespectrométricas tanto estão associadas às áreas com alterações metassomáticas quanto sobrepostas com lineamentos magnetométricos, por exemplo, a ZCSR, e altos topográficos, por exemplo, Serra do Ajarani e morros alinhados NW-SE e E-W. 

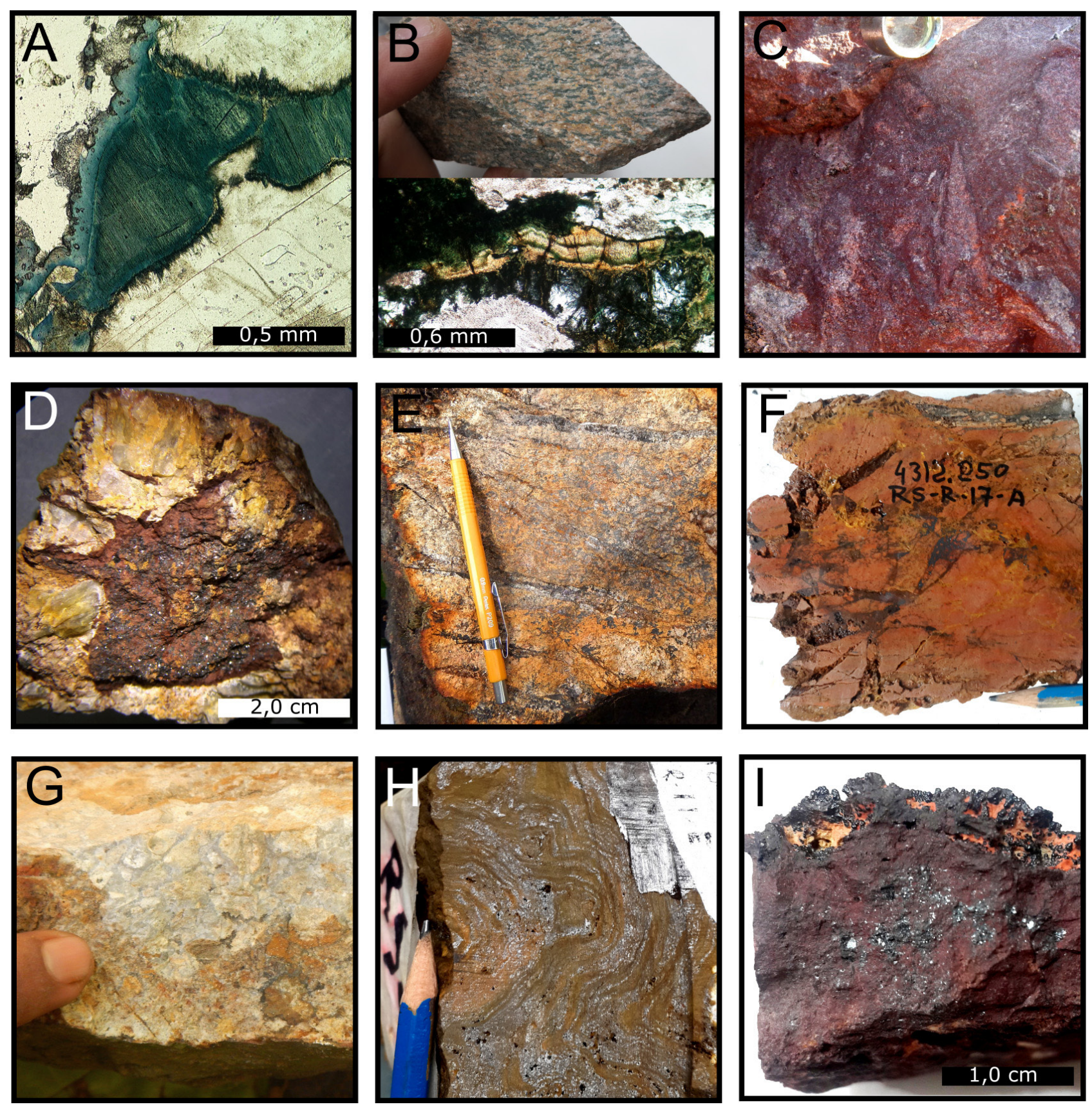

Figura 3 - A) RB-170, charnockitoide, substituição parcial de clinopiroxênio para riebeckita com halo do mesmo mineral. Pol. //. B) RB-159, fenito, composto por microclínio e pseudomorfos de aegirina fibro-radiados e coloformes pós-quartzo. Provável protólito ortognáissico. Estrutura milonítica mimetizada. Pol. //. C) RS-009B, brecha cataclásticahidrotermal composta essencialmente por quartzo, limonita/goethita e monazita. D) RS-007A, veio de quartzo com torita, brockita (marrons) e hematita especular (cinza) intercrescidos. E) RS-001A, rocha sienítica, metassomática,

composta por microclínio, quartzo, apatita e pirita cortada por vênulas de barita coberta por óxi-hidróxidos de manganês. F) RS-017A, brecha cataclástica-hidrotermal com clastos compostos por microclínio vermelho e matriz de calcedônia e hematita especular. G) LA-009A, brecha hidrotermal composta por clastos de quartzo e calcedônia (rocha silicificada) com matriz de quartzo. H) RS-011E, Rocha composta por bandas milimétricas intercaladas de quartzo e limonita. I) RS-011B, Ferritorita com hematita especular, intemperizada e com goethita botroidal e caulim associados.

\section{Detalhamento das novas ocorrências}

Foram descritos cinco alvos delimitados pela modelagem espacial (Figura 3 e Tabela 1):

I) Serra do Ajarani, RS-009 e 010 (Figura 3C): Afloram ortognaisses do SRU, frescos e silicificados, cortados por veios de quartzo (branco e fumê) e brecha cataclástica-hidrotermal de cor vermelha a rósea, de granulação fina, compostos por quartzo, óxidos e hidróxidos de Fe (hematita/limonita) e monazita, esta identificada por DRX. Esses veios, brechas e rochas silicificadas sustentam a serra homônima alinhada NW-SE. Excluindo-se os lateritos, entre as amostras analisadas pelo projeto, a RS-009B foi a que apresentou maior teor de ETR totais, no mínimo, 2,50\%. Na estação RS-010 há presença de blocos e matacões de lateritos limoníticos radioativos com valores altos de $\mathrm{MnO}$ (8,62\%), $\mathrm{BaO}$ (1,88\%), Cu (329 ppm), Pb (7.622 ppm), Zn (446 ppm), Th (2.393 ppm) e ETR (> 11.568 ppm). 
Tabela 1 - Dados litogeoquímicos. Óxidos em porcentagem em peso e elementos em partes por milhão. BS: Brecha

Silicosa; Ft: Ferritorita; Lt: Laterito; Mts: Metassomatito; RQL: Rocha quartzo-limonítica; VQH: Veio de quartzo e

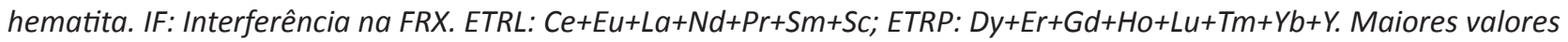
em negrito (fora a Ft). "> valor": sobrelimite de detecção.

\begin{tabular}{|c|c|c|c|c|c|c|c|c|c|c|}
\hline Amostra & Rocha & Lat & Long & $\mathrm{SiO}_{2}$ & $\mathrm{Fe}_{2} \mathrm{O}_{3}$ & $\mathrm{MnO}$ & $\mathrm{P}_{2} \mathrm{O}_{5}$ & $\mathrm{P}$ & $\mathrm{BaO}$ & $\mathrm{Ba}$ \\
\hline LA-0007 & Lt & 2,29454 & $-61,64947$ & 3,46 & $\mathbf{7 8 , 2 0}$ & 0,57 & 1,92 & - & 0,14 & - \\
\hline LA-0008 & Lt & 2,29729 & $-61,65103$ & $\mathrm{IF}$ & $\mathrm{IF}$ & $\mathrm{IF}$ & $\mathrm{IF}$ & $>10000$ & $\mathrm{IF}$ & 2210 \\
\hline LA-0009A & BS & 2,29754 & $-61,65595$ & $\mathbf{9 3 , 5 0}$ & 3,03 & 0,02 & 0,11 & - & $<0,01$ & 235 \\
\hline RS-0001A & Mts & 2,23353 & $-61,66106$ & 48,90 & 10,60 & 0,16 & 4,96 & - & 0,89 & - \\
\hline RS-0003B & VQH & 2,23456 & $-61,68562$ & 90,30 & 7,04 & 0,02 & 0,53 & - & 0,07 & - \\
\hline RS-0006A & Lt & 2,23944 & $-61,58145$ & 27,30 & 48,40 & 1,64 & 2,27 & - & 0,79 & - \\
\hline RS-0007D & Lt & 2,23859 & $-61,57890$ & 7,21 & 23,50 & 3,48 & 13,94 & - & 15,10 & - \\
\hline RS-0009B & BS & 2,14190 & $-61,53252$ & 73,60 & 17,70 & 0,02 & 1,99 & - & 0,16 & - \\
\hline RS-0010 & Lt & 2,14933 & $-61,53246$ & 4,86 & 60,10 & 8,62 & 0,66 & - & 1,88 & - \\
\hline RS-0011B & Ft & 2,12709 & $-61,33084$ & IF & IF & IF & IF & 3199 & IF & 88 \\
\hline RS-0011E & RQL & 2,12709 & $-61,33084$ & 76,10 & 20,20 & 0,43 & 0,103 & - & 0,03 & - \\
\hline RS-0012 & Lt & 2,13919 & $-61,25945$ & 18,40 & 55,60 & 0,01 & 0,14 & - & $<0,01$ & 20 \\
\hline
\end{tabular}

\begin{tabular}{|c|c|c|c|c|c|c|c|c|c|}
\hline Amostra & Cu & Pb & Zn & Nb & U & Th & ETRL & ETRP & IETR \\
\hline LA-0007 & 96 & 107 & 824 & 31 & 89 & 1670 & 14457 & 322 & 14779 \\
\hline LA-0008 & 38 & 400 & 893 & 908 & 346 & 7936 & $>32671$ & 1658 & $>34328$ \\
\hline LA-0009A & 1 & 51 & 71 & 50 & 4 & 141 & 815 & 160 & 975 \\
\hline RS-0001A & 15 & 14 & 128 & 36 & 30 & 4937 & 1943 & 1656 & 3599 \\
\hline RS-0003B & 13 & 101 & 50 & 20 & 48 & 4700 & 1479 & 2101 & 3579 \\
\hline RS-0006A & 121 & 2359 & 941 & 149 & 50 & $>10000$ & $>5425$ & $>2475$ & $>7900$ \\
\hline RS-0007D & 57 & 5996 & 1968 & 181 & 16 & 2499 & $>5874$ & 1477 & $>7351$ \\
\hline RS-0009B & 11 & 171 & 28 & 380 & 40 & 377 & $>24927$ & 659 & $>25586$ \\
\hline RS-0010 & 329 & 7622 & 446 & 27 & 43 & 2393 & $>11468$ & 100 & $>11568$ \\
\hline RS-0011B & 16 & 287 & 203 & 25 & 7129 & $>10000$ & $>9153$ & $>5998$ & $>15152$ \\
\hline RS-0011E & 1 & 117 & 340 & 1 & 3 & 257 & 115 & 42 & 157 \\
\hline RS-0012 & 15 & 27 & 49 & 79 & 7 & 959 & 129 & 95 & 225 \\
\hline
\end{tabular}

II) Sítio DNC, RS-006 e 007 (Figura 3D): Presença de crosta laterítica radioativa composta por porções manganesíferas, mais maciças, lateritos limoníticos porosos e pisólitos limoníticos. Também foram encontrados blocos de quartzo, de caulim e um bloco de quartzo com hematita especular, torita e brockita (definidos por DRX). Os lateritos apresentam valores elevados de $\mathrm{Pb}$ (2.358 ppm), Zn (941 ppm), Th (> $10.000 \mathrm{ppm}$ ) e ETR totais (>7.900 ppm) sendo que a amostra RS-007D é muito rica em $\mathrm{P}_{2} \mathrm{O}_{5}$ $(13,94 \%)$ e $\mathrm{BaO}(15,10 \%)$. Localmente afloram ortognaisses do SRU.

III) Barita, RS-001, 003, 017 e 018 (Figuras 3E e $3 F$ ): Afloram rochas gabroicas, relacionadas à $S R$, intrusivas nos ortognaisses do SRU. Foram encontrados blocos de rochas de composição sienítica, de cor salmão, radioativas, compostas por microclínio, quartzo, apatita e pirita, por vezes brechada com ma- triz de hematita especular e calcedônia. Pelas feições encontradas (bandamento, lentes de quartzo e mineralogia) acredita-se que seja um metassomatito. Ao se partir esse tipo de rocha, ocorre um odor fétido semelhante ao do gás de cozinha. Em alguns matacões, há vênulas de quartzo e siderita, de barita e de hematita especular. Blocos centimétricos de barita azulada e de quartzo com hematita especular são comuns. A amostra RS-001A apresenta altos teores de $\mathrm{P}_{2} \mathrm{O}_{5}(4,96 \%)$ Th (4.937 ppm) e ETR (3.599 ppm). Também se observa regiões ricas em fraturas nas rochas gabroicas com halos centimétricos de metassomatismo alcalino. Afloram também blocos de tefritos com esparsos xenólitos do gabro encaixante.

IV) Queixada, LA-007, 008 e 009 (Figura 3G): A forte anomalia aerogamaespectrométrica desse alvo é explicada pela presença de lateritos radioativos, limoníticos/goethíticos maciços a bandados e que susten- 
tam um morro com feições geomorfológicas de dissolução. Esses lateritos são ricos em ETR (14.779 a > 34.328 ppm) e Th (1.670 a 7.936 ppm) e anômalos em Pb (107 a 400 ppm), Zn (824 a 893 ppm), Nb (31 a 908 ppm) e U (89 a 346 ppm). Na área mais baixa afloram ortognaisses do SRU cortados por vênulas de riebeckita e brechas silicosas anômalas em Th (141 ppm).

V) Serra do Repartimento Leste, RS-011 e 012, (Figuras 3H e 3I): Na continuidade leste da feição topográfica da Serra do Repartimento, foram encontrados blocos e matacões de quartzo de veio branco cortado por brechas silicosas com limonita associada, em alguns locais com um bandamento concêntrico ("rocha quartzo-limonítica"). Também foi encontrado um bloco de torita (definida por DRX) intercrescida com hematita especular e goethita ("ferritorita"). Além dessas, também afloram agregados de pisólitos e pisólitos limoníticos. A "rocha quartzo-limonítica" e os pisólitos são anômalos em Th (257 e 959 ppm, respectivamente).

\section{THORIUM VEINS}

Veios hidrotermais enriquecidos em Th e ETR foram agrupados em um modelo descritivo chamado Thorium Veins cujas principais características estão descritas em STAATZ (1992). O modelo descreve veios de quartzo, k-feldspato e "óxidos de ferro" (i.e., limonita/goethita/hematita) com diversos minerais contendo Th e/ou ETR em sua composição, principalmente torita, monazita e brockita. Esses veios possuem associação com corpos de rochas alcalinas diversas enriquecidas em Th e também carbonatitos, podendo apresentar uma faixa de fenitização associada. A Figura 4 mostra o esquema geométrico desse tipo de depósito, mostrando sua relação com uma intrusão alcalina e diques carbonatíticos. Esse tipo de depósito se destaca por hospedar as maiores reservas e os maiores teores de Th dos EUA (VAN GOSEN; GILLERMAN; ARMBRUSTMACHER, 2009).

\section{GUIAS PROSPECTIVOS}

Dentre as feições observadas nessas ocorrências, podemos destacar as características mais marcantes como guias prospectivos em campo: i) cintilometria acima de 1.000 cps; ii) deformação rúptil, normalmente com halos de metassomatismo associados; iii) substituição de feldspatos por feldspato potássico avermelhado; iv) vênulas de riebeckita; v) odor fétido ao se partir essas rochas hidrotermalizadas; vi) brechas silicosas e; vii) lateritos radioativos.

\section{CONCLUSÕES}

A área que compreende as folhas NA.20-X-C-VI (Serra do Ajarani) e NA.20-X-C-IV (Serra da Prata), deve ser considerada estratégica, pois apresenta maior potencial para conter mineralizações associadas com rochas alcalinas diversas, seus produtos de alteração intempérica e processos hidrotermais associados. Foram delimitadas novas regiões potenciais com a utilização de modelagem espacial. Em importância, destaca-se o entorno da ZCSR, uma faixa, aproximadamente E-W, com $75 \mathrm{~km}$ de extensão e a Serra do Ajarani e morros alinhados NW-SE com $25 \mathrm{~km}$ de extensão onde afloram rochas enriquecidas em Th e anomalamente radioativas. Essas áreas apresentam um alto potencial para mineralizações de ETR, Th, U, $\mathrm{P}, \mathrm{Nb}$ e Ba além de mostrar-se como ambiente geológico altamente favorável para rochas carbonatíticas.

As semelhanças encontradas com

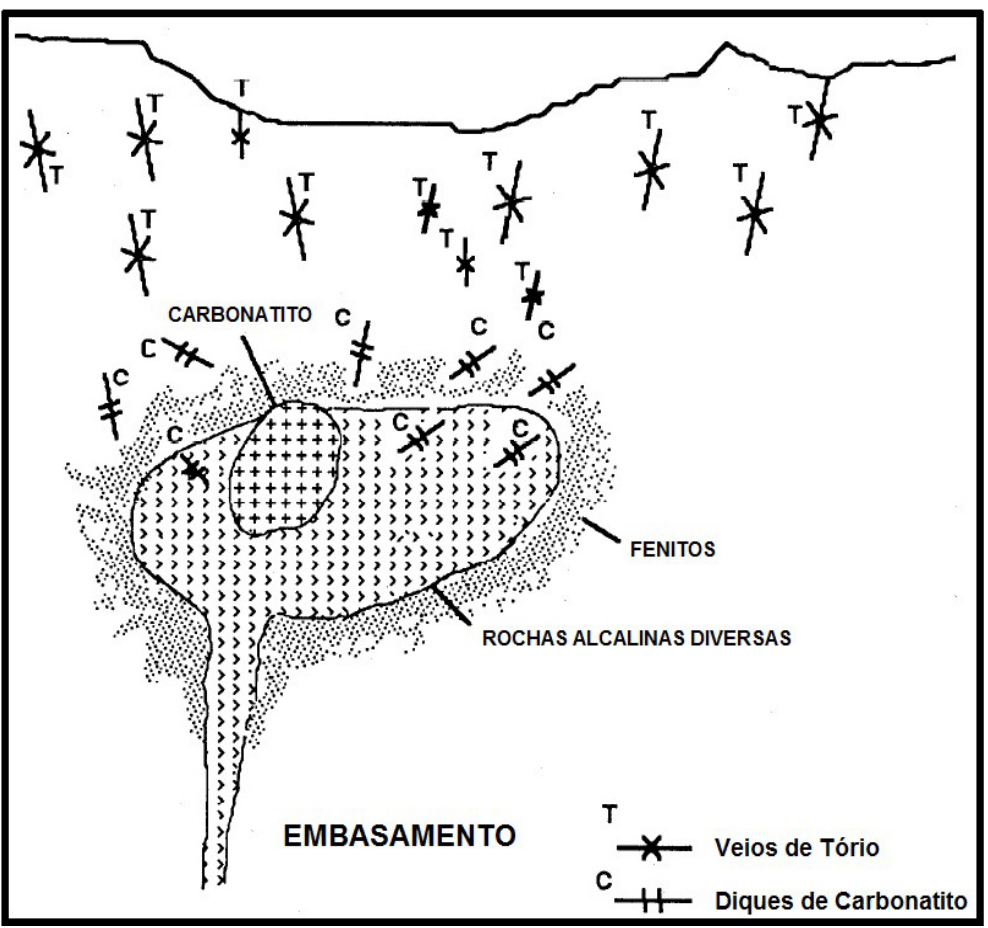
o modelo descritivo de Thorium Veins levam a crer que esse modelo possa ser usado como base para o entendimento das mineralizações de Th-ETR da área e ajudar a delinear características prospectivas regionais.

\section{AGRADECIMENTOS}

Agradecemos à Sociedade Geral de Mineração LTDA e ao geólogo Marcelo R. S. Almeida pelas contribuições e apoio.

\section{REFERÊNCIAS BIBLIOGRÁFICAS}

ALMEIDA, M. E.; OLIVEIRA, A. C. S. Geologia e geocronologia U-Pb em zircão da suíte alcalina Apiaú, Campos Novos, Roraima. In: CONGRESSO BRASILEIRO DE GEOLOGIA, 49., 2018, Rio de Janeiro, RJ. Anais [...]. Rio de Janeiro: SGB, 2018. p. 1861.

Figura 4 - Esquema do modelo de Thorium Veins (TV) por Staatz, 1992. 
BOMFIM, L. F. C.; RAMGRAB, G. E; UCHOA, I. B.; MEDEIROS, J. B.; RIBAMAR FILHO, J.; MANDETTA, P. V.; KVYUMJIAN, R. M.; PINHEIRO, S. S. Projeto Roraima: relatório final. Manaus: CPRM, 1974. v. I A-D e v. II.

BORGES, F. R. Projeto Serra do Repartimento: relatório de progresso. Manaus: CPRM, 1990. 30 p.

BRANDÃO, R. L.; FREITAS, A. F. Serra do Ajarani, Folha NA.20.X-C-VI: estado de Roraima. Manaus: CPRM, 1994. 153 p.

CAMARO, C. A. B. Geologia e gênese das ocorrências de Ti, Nb e ETR's na Serra do Repartimento, Roraima. 2017. 174 p. Dissertação (Mestrado) - Instituto de Ciências Exatas, Universidade Federal do Amazonas, Manaus, 2017.

COMPANHIA DE PESQUISA DE RECURSOS MINERAIS. Projeto Uraricoera, levantamentos aerogamaespectrométrico e aeromagnetométrico, Território Federal de Roraima: relatório final. Rio de Janeiro: PROSPEC, 1978. 1 v. +2 caixas.

EIRAS, J. F.; KINOSHITA, E. M. Evidências de movimentos transcorrentes na bacia do Tacutu. In: CONGRESSO BRASILEIRO DE GEOLOGIA, 35., 1988, Belém, PA. Anais [...]. Belém: SBG, 1988.

FRAGA, L. M. B.; ARAÚJO, R. V.; DUARTE, B. P. Igneous charnockitic rocks of the Kanuku Complex and Serra da Prata Suite in the Central Guiana Belt (CGB), Roraima State, Brazil. In: INTERNATIONAL SYMPOSIUM ON GRANITES AND ASSOCIATED ROCKS, 2., 1997, Salvador, BA. Resumos [...]. Salvador, 1997. 3 p.

FRAGA, L. M. B.; ARAÚJO, R. V. Suíte intrusiva Serra da Prata. Roraima Central, Folhas NA.20-X e NA.21-V, Estado de Roraima, 1:500.000. Brasília: CPRM, 2000. p. 83-89. 1 CD-ROM.

FRAGA L. M. A Associação Anortosito-Mangerito-Granito Rapakivi (AMG) e suas encaixantes paleoproterozoicas: evolução estrutural, geocronologia e petrologia. 2002. $351 \mathrm{f}$. Tese (Doutorado) - Centro de Geociências, Universidade Federal do Pará, Belém, PA, 2002.

FIGUEIRÊDO, R. F. Contexto tectônico do Complexo Alcalino Apiaú-Roraima: aerogeofísica, petrologia e geocronologia U-Pb. 2016. 106 f. Dissertação (Mestrado) - Instituto de Geociências, Universidade Estadual de Campinas, Campinas, SP, 2016.

HEINONEM, A.; FRAGA, L. M.; RAMO, O. T.; DALL'AGNOL, R. MANTTARI, I; ANDERSEN, T. Petrogenesis of the igneous Mucajaí AMG complex, northern Amazonian craton - geochemical, U-Pb geochronological, and $\mathrm{Nd}-\mathrm{Hf}-\mathrm{O}$ isotopic constraints. Lithos, $\mathrm{v}$. 15, p. 17-34, 2012. DOI: https://doi.org/10.1016/j. lithos.2011.07.016.

LE BAS, M. J. Carbonatite magmas. Mineralogical Magazine, v. 44, p. 133-140, 1981. DOI: https://doi. org/10.1180/minmag.1981.044.334.02
MARZOLI, A.; RENNE, P. R.; PICCIRILO, E. M. ERNESTO, M.; BELLIENI, G.; DE MIM, A. Extensive 200-million-year-old continental flood basalts of the Central Atlantic magmatic province. Science, v. 284, n. 5414, p. 616-618, 1999.

MONTALVÃO, R. M. G.; MUNIZ, M. B.; ISSLER, R. S.; DALL'AGNOL; LIMA, M. I. C.; FERNANDES, P. E. C. A.; SILVA, G. G. Geologia In: BRASIL. Departamento Nacional da Produção Mineral. Projeto RADAMBRASIL. Folha NA.20-Boa Vista e parte das folhas NA.21-Tumucumaque, NB.20-Roraima e NB.21. Rio de Janeiro, 1975. cap. I, p. 13-136. (Levantamento de Recursos Naturais, 8).

MOURÃO, L. M. F. Projeto Rio Branco: relatório final e anexos. Rio de Janeiro: CPRM, 1984. Inclui mapas.

OLIVEIRA, V. S.; PITARELLO, M. Z.; REIS, N. J.; LOPES, P. R.; AGUIAR, L.; SILVA, S. R. A.; GARCINDO, L. B. G.; SOUZA, A. G. H.; CAVALCANTI, R.; QUEIROZ, L.; RAMOS, M. N. Modelagem espacial aplicada a identificação de rochas alcalinas e corpos máficos na região centro-sudeste de Roraima. In: CONGRESSO BRASILEIRO DE GEOLOGIA, 48., 2016, Porto Alegre, RS. Anais [...]. Porto Alegre: SGB, 2016.

REIS, N. J.; FRAGA, L. M.; FARIA, M. S. G.; ALMEIDA, M. E. Geologia do Estado de Roraima, Brasil. Geologie de la France, 2003, n. 2 - 4, p. 121-134, 2003.

REIS, N. J.; FARIA, M. S. G.; ALMEIDA, M. E.; OLIVEIRA, M. A. Folhas NA.20 Boa Vista e NB.20 Roraima. In: CPRM - SERVIÇO GEOLÓGICO DO BRASIL. Carta Geológica do Brasil ao Milionésimo: sistema de informações geográficas-SIG. [Geological Map of Brazil 1:1.000.000 scale: geographic information system-GIS]. Brasília: CPRM, 2004. CD-ROM 2/41.

SANTOS, J. O. S.; SOUZA, M. M.; PRAZERES, W. V.; MOREIRA, A. S. Projeto Norte da Amazônia: Domínio Baixo Rio Negro. Manaus: CPRM. 1974, 8 v.

SANTOS, J. O. S.; REIS, N. J.; HARTMANN, L. A.; MCNAUGHTON, N. J. Associação Anortosito-Charnockito-Rapakivi no Calimiano do Norte do Cráton Amazônico, Estado de Roraima, Brasil: evidências da geocronologia U-Pb (SHRIMP) em Zircão e Baddeleyita. In: SIMPÓSIO DE GEOLOGIA DA AMAZÔNIA, 6., 1999. Resumos Expandidos [...]. Manaus: SGB, 1999. p. 502-505.

SAWATZKY, D. L.; RAINES, G. L.; BONHAM-CARTER, G. F.; LOONEY, C. G. Spatial Data Modeller (SDM): ArcMAP 9.3 geoprocessing tools for spatial data modelling using weights of evidence, logistic regression, fuzzy logic and neural networks, 2009.

SOUZA, F. J. C. Projeto Serra do Repartimento, Bloco Apiaú: relatório global de pesquisa, alvarás $3074 / 87$, 750/88 e 1135/88, DNPM 880.037/85, 880.039/85 e 880.041/85. Manaus: CPRM, 1989. 88 p.

STAATZ, M. H. Descriptive model of thorium-rare-earth veins. In: BLISS, J. D. (ed.). Developments in mineral deposit modeling. Washington: USGS, 1992. p. 13-15, 1992. (U.S. Geological Survey Bulletin, 2004). 
TAKEHARA, L. (org.). Projetos Fosfato e Terras Raras (ETR) do Brasil - estado de Roraima: área Campos Novos. Manaus: Serviço Geológico do Brasil - CPRM, [2019?]. (Informe de Recursos minerais. Série Minerais Estratégicos). No prelo.
VAN GOSEN, B. S.; GILLERMAN, V. S.; ARMBRUSTMACHER, T. J. Thorium deposits of the United States-Energy resources for the future?. United States Geological Survey. Circular, 1336, 21 p., 2009.

\section{INFORME TÉCNICO N 17}

Brasilia, novembro de 2019.

ISSN: 2448-2242

Publicação on-line seriada

Serviço Geológico do Brasil - CPRM

Disponível em: www.cprm.gov.br

\section{Serviço Geológico do Brasil - CPRM}

SBN - Quadra 02 - Bloco H, Ed. Central Brasília, $1^{\circ}$ andar Brasília - DF - Brasil

CEP: 70040-904

Telefone:(61) 2108-8400

www.cprm.gov.br

contatos: seus@cprm.gov.br evandro.klein@cprm.gov.br
Diretor de Geologia e Recursos Minerais José Leonardo Silva Andriotti

\section{Corpo Editorial}

Evandro Luiz Klein (Editor)

João Henrique Larizzatti

Luiz Gustavo Rodrigues Pinto

\section{Revisora}

Lucy Takehara Chemale

Normalização Bibliográfica

Nelma Fabrícia da P. Ribeiro Botelho

\section{Editoração Eletrônica}

Marcelo Henrique Borges Leão

Nelma Fabrícia da P. Ribeiro Botelho
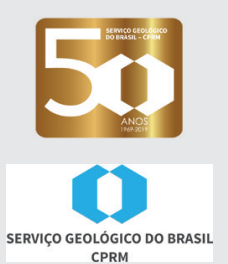